\title{
A TEMÍVEL SIMETRIA DO VAMPIRO: INTERSTÍCIO DE SIGNIFICAÇÃO ENTRE WILLIAM BLAKE EM ANNE RICE
}

\begin{abstract}
Andrio J. R. dos Santos ${ }^{1}$
Resumo: No romance The Tale Of The Body Thief (1991), Anne Rice aborda o poema iluminado The Tyger, de William Blake, como uma forma de discutir o tema do mal, assim como a malignidade que o vampiro protagonista, Lestat, reconhece em si mesmo. Tal questão é explorada a partir da possibilidade do personagem recuperar sua humanidade, uma vez que ele foi transformado em vampiro à força. Desse modo, pretendo desenvolver um estudo investigativo acerca das significações intercambiáveis entre as obras de Rice e Blake. Para dar conta desse problema de pesquisa, trabalho a partir das concepções teóricas da tradução intersemiótica. Sigo pela via proposta por autores como Diniz (1998), Clüver (2006) e Plaza (2008), que compreendem tradução intersemiótica essencialmente como um diálogo de significados intermídia e sempre em expansão.Tal concepção permite investigar e discutir a maneira como Rice reinterpreta, traduz e recria as significações da poesia e da pintura blakeanas em seu romance. A partir de tais aparatos teóricos, é possível considerar que o poema de Blake é semioticamente traduzido por Rice em duas instâncias. Na primeira delas, The Tyger opera como uma metáfora para a natureza do próprio vampiro Lestat, um predador terrível e belo, sublime em sua própria imagem. Na segunda instância, The Tyger relaciona-se com o romance de forma remissiva, diretamente ativa em relação à construção do enredo da obra.
\end{abstract}

Palavras-chave: Tradução Intersemiótica. Identidade. Anne Rice. William Blake.

\begin{abstract}
In the novel The Tale Of The Body Thief (1991), Anne Rice mentions the illuminated poem The Tyger, by William Blake, as a subject in the discussion concerning about the theme of evil and the malignity that the main character, called Lestat, sees in himself. This subject is approached by the possibility of Lestat regaining his humanity, since he was turned into a vampire by force. Therefore, I aim to develop an analytic study concerning the Interchangeable meanings between Rice's and Blake's works. To cover this analysis subject I approach the theorical conceptions related to intersemiotic translation. I follow the propositions made by authors like Diniz (1998), Clüver (2006) and Plaza (2008), who comprehends intersemiotic translation essentially as dialogical process of intermedia meanings, which it's always in movement. This proposition allows me to discuss which Rice reread, translate, and recreates Blake's poetry and painting in her novel. By these theorical resources it's possible to consider that Blake's poem is semioticly translated in two instances. In the first one, The Tyger presents itself as a metaphor to the nature of Lestat, a handsome and terrible beast, sublime in his own way. In the second, the poem relates itself in a remissive manner, operating directly over the novel's structure and plot.
\end{abstract}

Keywords: Intersemiotic translation. Identity. Anne Rice. William Blake.

\footnotetext{
${ }^{1}$ Doutorando em Letras - Estudos Literários (UFSM). E-mail: andriosantoscontato@hotmail.com.
} 


\section{Introdução}

Anne Rice é uma autora americana nascida em New Orleans. O início de sua carreira foi marcado pela publicação de Interview with the Vampire (1976) adaptado para o cinema em 1994 - primeiro volume da saga pela qual Rice é mais conhecida, The Vampire Chronicles. Segundo Jennifer Smith (1996), a ficção de Anne Rice mescla características advindas de gêneros que tratam do sobrenatural na literatura, como o horror, o gótico e o fantástico. Segundo a autora, tais gêneros ascenderam durante o século XIX. Os escritores românticos rejeitavam a ideia de que tudo poderia ser explicado pela lógica cientificista em voga, mantendo um ideal no inexplicável, no místico e no mítico: "Romantic literature emphasizes strong ties to nature as both wild and true, na acceptance of the supernatural as a real force in life, na appreciation for passion over logic, and a rejection of conventional rules or rituals" (SMITH, 1996, p. 11) ${ }^{2}$. Smith vai além de traçar considerações sobre os três gêneros supracitados, afirmando que Anne Rice é uma escritora romântica do século XX.

No romance The Tale Of The BodyThief (1991), Anne Rice aborda o poema The Tyger, de William Blake, como uma forma de discutir o tema do mal, assim como a questão da malignidade que o vampiro protagonista, Lestat, reconhece em si mesmo. Desse modo, pretendo desenvolver um estudo investigativo acerca das significações intercambiáveis entre as obras de Rice e Blake. Para dar conta desse problema, pretendo trabalhar a partir das concepções teóricas que norteiam a questão da tradução intersemiótica. Intento seguir pela via proposta por autores como Diniz (1998), Clüver (2006) e Plaza (2008), que compreendem tradução intersemiótica essencialmente como um diálogo de significados intermídia e sempre em expansão. Tal concepção permite investigar e discutir a maneira como Rice reinterpreta, traduz e recria as significações da obra iluminada blakeana em sua produção romanesca.

\footnotetext{
${ }^{2} \mathrm{~A}$ literatura romântica enfatiza fortes laços com a natureza, vista ao mesmo tempo como selvagem e autêntica, também uma aceitação do sobrenatural como uma força real na vida, uma predileção pela paixão em detrimento da lógica e uma rejeição de regras e rituais convencionais (Tradução do autor).
} 


\section{Concepções acerca de tradução intersemiótica}

Campo abrangente, a tradução intersemiótica encontra origens no trabalho de Roman Jakobson, um dos primeiros autores a discutir problemas que norteiam os tipos de tradução. Segundo o teórico, haveria três modalidades de tradução. A primeira delas, a interlingual, se refere a uma tradução entre diferentes línguas. A segunda, denominada de intralingual, abarca a tradução de textos dentro de mesma língua de origem. A terceira modalidade seria a intersemiótica, compreendida por Jakobson (2007) como uma transferência de sentido, uma transmutação de signos, que opera de um sistema verbal para outro sistema não verbal, ou seja, de outra natureza.

A semiótica de Charles Sanders Peirce foi fonte prolífica para os estudos de Jakobson. Lúcia Santaella esclarece que "a fenomenologia peirceana fornece as bases para uma semiótica antirracionalista, antiverbalista e radicalmente original, visto que nos permite pensar também como signos, ou melhor, como quase-signos, fenômenos rebeldes, imprecisos" (2002, p. 11). Ao conceber sua semiótica, Peirce objetivava uma espécie de ciência geral de todas as linguagens, passível de aplicação analítica, como uma ferramenta de investigação científica dos signos e dos processos de geração de sentido.

Todavia, Jakobson tratou de recortes específicos da semiótica periceana, questões essencialmente instrumentais. Nesse sentido, torna-se necessário observar que a linguagem é composta e integrada por processos comunicacionais complexos, os quais compreendem várias modalidades de geração de sentido. Partindo de Jakobson, Umberto Eco (2007) expandiu a ideia de tradução intersemiótica. Para o autor, as transformações de geração de sentido entre duas modalidades não se restringem a relações entre o verbal e 0 não verbal. Eco compreende que a tradução intersemiótica deve abranger múltiplas instâncias do verbal e do não verbal, relacionadas entre si.

A partir de concepções de Jakobson, Julio Plaza (2008) discute questões em torno da tradução intersemiótica e compreende este processo como uma transposição de sentidos, que se realiza em nível criativo, que dialoga e influencia mesmo na significação do original. Parte das ideias de Plaza advém do pensamento de Walter Benjamin, que compreende o passado como um projeto construtivo. Para 
Plaza, o passado é um ícone ativo que age sobre a operação de tradução, atualizando o objeto traduzido ao mesmo tempo em que este objeto traduzido mantém significações relativas a seu passado composicional. Em uma terceira instância, o objeto tradutor torna-se um símbolo, que significa de forma geral e abrangente, em múltiplas direções.

Plaza também é influenciado pelo trabalho de Peirce e sua concepção triádica do processo sígnico demonstra essa aproximação. Para Peirce (1975), um signo só se traduz através de outro signo. Na concepção de Plaza, o signo opera a partir de um devir, uma possibilidade de significar em um processo de semiose, de geração de sentido, infinito. Em seu estudo, Plaza concentra seus esforços analíticos no objeto dinâmico da semiótica peirceana. Segundo Santaella (2005), o objeto dinâmico é aquilo que o signo substitui no processo de geração de sentido. Vale ressaltar que este objeto não é o signo em si, mas uma espécie de representação, uma imagem capaz de significar no pensamento de um intérprete. Plaza trabalha a partir desse recorte, pois objetiva discutir uma concepção de "signo estético". Dessa forma, o autor compreende a tradução intersemiótica como um procedimento contínuo de interação, realizado a partir de uma operação similar ao processo de criação ou recriação artística.

Os autores Aguiar e Queiroz (2010) mencionam que a tradução intersemiótica, por ser um campo em expansão, ainda carece de definições metodológicas, sendo por essa razão que concentram seus esforços na definição da instância metodológica do processo. Os autores retomam Plaza e Peirce e, assim, consideram tradução intersemiótica como uma operação multiestruturada, isto é, um processo de geração de sentido que se realiza a partir da conjunção de diversas instâncias ou fenômenos, como o da transculturação.

Como uma definição inicial desse processo de transferência e geração de sentido, considero concepções de Diniz (1998), assim como de Plaza (2008), que compreendem cada operação semiótica como um processo fundamentado em seu próprio sistema. Nessa perspectiva, os problemas envolvidos no processo de tradução intersemiótica se relacionam com uma investigação crítica do processo pelo qual um objeto tradutor ressignifica um objeto traduzido. Desse modo, tradução intersemiótica diz respeito a um diálogo entre signos. De acordo com Plaza: 
Tradução como prática crítico-criativa na historicidade dos meios de produção e re-produção como leitura, como metacriação, como ação sobre estruturas e eventos, como diálogo de signos, como síntese e reescritura da história. Quer dizer: como pensamento em signos, como trânsito dos sentidos, como transcriação de formas na historicidade (PLAZA, 2008, p. 14).

O autor concebe o processo de tradução intersemiótica não apenas como uma investigação crítica, mas também como uma prática criativa. Essa concepção advém, em parte, da influência exercida pelo poeta e tradutor Haroldo de Campos, influência reconhecida pelo próprio Plaza em seu texto. Para Campos (2006), toda tradução se realiza como uma recriação poética, um processo que se funda na leitura crítica.

Calcado nas considerações supracitadas, é possível considerar tradução intersemiótica como um processo múltiplo, compreendido em variadas instâncias. Primeiramente, este tipo de operação semiótica se realiza como uma transferência ou diálogo de significados entre diferentes sistemas simbólicos. Todavia, o processo de tradução intersemiótica se estende além da relação entre dois sistemas sígnicos, compreendendo também um diálogo ativo de significações, operação de atualização mútua tanto do objeto tradutor quanto do traduzido, atuante entre diferentes mídias e/ou contextos. A principal característica do processo seria sua constante expansão, tal como ressaltada por Claus Clüver. Para o autor, este processo compreende "a existência de um equivalente de essência, a evocação de uma realidade não representada diretamente pela denotação das palavras, ou pelas marcas visuais" (2006, p. 108).

\section{Tradução intersemiótica em The Tale Of The Body Thief e The Tyger}

The Tale Of The Body Thief (1991) é o quarto volume da saga The Vampire Chronicles. O romance é protagonizado pelo personagem Lestat de Lioncourt. Kathryn McGinley (1996) menciona que Lestat é um heroi byroniano que descreve a si mesmo com vaidade: "[h]e is an eighteenth-century French lord, the son of a marquis, made into a vampire because of his passion for life and his steadfast defiance. $\mathrm{He}$ is another noble outlaw, the aristocratic rebel, the one who craves 
power and independence" (MCGINLEY, 1996, p. 82) ${ }^{3}$.Ainda assim, Lestat também se mostra dramático e possuidor de uma enorme necessidade de pertencimento e conexão, características expressas, segundo Ray B. Browne(1996) e Gary Hoppenstand (1996), através do enredo: a personagem é frequentemente abandonada por aqueles por quem se apaixona.

Um dos temas explorados em The Tale Of The Body Thief(1991) é a questão da humanidade perdida de Lestat. No romance, o personagem recebe a possibilidade de ter sua mortalidade reestabelecida. $O$ vampiro é abordado por Reglan James, um homem que possui o poder de se projetar de forma astral. James oferece a Lestat uma troca de corpos. O vampiro ficaria com o corpo de James, um jovem de vinte e quatro anos de idade, enquanto James ficaria com seu corpo de vampiro por vinte e quatro horas.

A questão da troca de corpos tem relação direta com a maior angústia de Lestat: ele é constantemente atormentado pela noção de que foi condenado a ser mal, quando teria desejado ser bom. Percebendo-se incapaz de ser bom, ele decide dedicar-se a ser bom sendo mal. Em The Vampire Lestat (1987), Lestat menciona que "I was a good marksman when I was a young man, [...], a good actor on the stage. And now I am a good vampire. So much for our understanding of the word good" (RICE, 1987, p. 253). No segundo volume da série, Lestat foi transformado contra a sua vontade pelo vampiro Magnus. É justamente por isso que ele não pode negar o pedido de James de trocar de corpos. Se o fizesse, teria escolhido o mal e renegado a única possibilidade de ser bom e de alcançar a redenção.

No primeiro capítulo de Body Theif, Lestat conta que teve um sonho com seu amigo David Talbot, um estudioso de 74 anos de uma ordem ocultista chamada Talamasca. No sonho, David é jovem e está em uma floresta caçando um tigre. $\mathrm{O}$ protagonista percebe o animal muito próximo e tenta alertar David sobre o perigo iminente. Mais tarde, Lestat vê a pele do tigre na sala de estar do amigo, que afirma

\footnotetext{
${ }^{3}$ Ele é um senhor de terras Francês do século XVIII, o filho de um marquês, transformado em vampiro devido a sua paixão pela vida e seu ímpeto inabalável. Ele é outro nobre marginal, o rebelde aristocrata, aquele que anseia por poder e independência (Tradução do autor).

${ }^{4}$ Eu era um bom atirador quando eu era jovem, [...], um bom ator no palco. E agora eu sou um bom vampiro. Tanto para a sua compreensão da palavra bom (Tradução do autor).
} 
ter realmente caçado o tigre em sua juventude: "This is young David Talbot of years and years ago, when his heart didn't beat so fast within his chest. Yet he is in danger. Tyger, tyger burning bright. Is that his voice, whispering those words or is it mine?" $(\text { RICE, 1993, p. 6) })^{5}$.

Lestat associa o tigre a si mesmo ao mencionar que sua última vítima era um assassino: "I meant to put na end to the killer. He was a man-eating tiger, my brother" (RICE, 1993, p. 61) ${ }^{6}$.Nessa acepção, o poema The Tyger, do livro iluminado Songs of Innocence and of Experience (1789), serve como um emblema para a natureza de Lestat. Para Foster Damon (2005), o poema de Blake representa ira divina em contraste com o cordeiro, que representaria o amor ou a redenção divina. Segundo Harold Bloom (2003), os vinte e quatro versos que compõe o poema levantam questões acerca de um trabalho criativo. Tavares (2012) menciona que as questões levantadas pelo eu lírico são semelhantes às realizadas por Jó a Deus, no Livre de Jó.

O poema de Blake questiona a criação de algo bondoso, como o cordeiro, em contraste com a criação de algo temível, como o tigre: "[d]id He Who made the Lamb make thee?" (BLAKE, 1795, v. 22) ${ }^{7}$. Contudo, Bloom (2003) destaca que o tigre não representa o mal ou a versão maligna do cordeiro. Compreender os poemas simplesmente a partir de um maniqueísmo dualista religioso seria reducionista em relação à metáfora proposta por Blake: o assombro da criação divina, pois o mesmo deus que criara o cordeiro teria criado o tigre. Em certas instâncias, como comenta Tavares (2012), o tigre e o cordeiro podem ser lidos respectivamente como emblemas simbólicos para as concepções blakenas de experiência e inocência. É nessa acepção que se estabelece a relação de Lestat com o poema The Tyger. Na primeira estrofe do poema de Blake, o eu lírico questiona que tipo de força criativa teria forjado tal temível criatura:

\footnotetext{
${ }^{5}$ Este é um David jovem de anos e anos atrás, quando seu coração não batia tão rápido dentro de seu peito. Ainda assim, ele está em perigo. Tigre, Tigre, brilho ardente. Aquela é a sua ou a minha voz, sussurrando tais palavras? (Tradução do autor).

${ }^{6}$ Eu intentei dar fim a um assassino. Ele era um tigre devorador-de-homens, meu irmão (Tradução do autor).

${ }^{7}$ Quem fez a ovelha te fez? (Tradução de Campos, 1979).
} 
Tyger Tyger. burning bright,

In the forests of the night:

What immortal hand or eye.

Could frame thy fearful symmetry?

(BLAKE, 1789, v. 1-4)

Lestat frequentemente levanta essa questão a respeito de si mesmo, sobre como poderia existir um Deus bondoso que tivesse criado algo tão pernicioso (aos seus olhos) como os vampiros. A resposta do eu lírico do poema vem também na forma de um questionamento: "[d]id He smile his work to see?" (BLAKE, 1789, v. $21)^{9}$. Ou seja, a grande questão acerca da própria existência de Lestat, que frequentemente o atormenta, é qual porção de sua existência foi concebida ou concedida por Deus e se essa possível divindade agradar-se-ia em alguma instância com sua criação vampírica, com a criação dessa criatura de natureza maligna.

Reitero que Lestat acredita ter tido sua inocência roubada pelo vampiro Magnus, ao ser sequestrado e transformado contra a sua vontade. Por isso ele aceita o trato com James, não só pela possibilidade de escolher o bem ao invés do mal que reconhece na sua natureza vampírica, como também na vã tentativa de roubar sua inocência de volta, como um dia ela foi tirada dele à força. Como Smith menciona,

For Lestat clearly believes in free will, that we choose our destinies on earth and are not simply pawns in the hands of fate. Over and over again, Lestat chooses his own path and boasts that he does so, yet in the back of his mind is always the knowledge that the greatest adventure of his life was begun by force and not by choice. Having given up his immortality knowing unconsciously that James would never give back his body, Lestat now gets a chance to consciously choose $(1996, \text { p. } 97)^{10}$.

\footnotetext{
${ }^{8}$ Tygre! Tygre! Brilho, brasa/ que a furna noturna abrasa,/ que olho ou mão armaria/ tua feroz symmetrya? (Tradução de Campos, 1979).

${ }^{9}$ Quem fez a ovelha te fez? (Tradução de Campos, 1979).

${ }^{10}$ Pois Lestat claramente acredita em livre arbítrio, que nós escolhemos nossos destinos na terra e não somos simplesmente peões nas mãos do destino. De novo e de novo, Lestat escolhe seu próprio
} 
Porém, ao viver como mortal, Lestat começa a se dar conta de sua verdadeira natureza, a qual o arrasta em direção a imagem predatória do tigre, ao invés da redentora do cordeiro. "[H]e must regain his body or lose his identity. This also reflects his character growth because he has attained enough self-knowledge not only to recognize the evil within himself, but also to embrace it as part of himself" (SMITH, 1996, p. 93) ${ }^{11}$. Assim, ele decide recuperar seu corpo, empreitada bem sucedida devido à ajuda de seu amigo David Talbot.

Lestat compreende o que ele é e, de certa forma, escolhe o mal. Não como maldade em si, mas como inversão moral: "'That's the only way the literal Devil can do good', I said. 'To play himself in a tableau to expose evil”' (RICE, 1993, p. 191) ${ }^{12} .0$ mal passa ser uma nova forma de ética para criaturas que estão apartadas da humanidade, embora a tangenciem, como os vampiros riceanos. Esse tipo de inversão moral relaciona-se diretamente com as concepções acerca de heróis românticos malditos e sombrios, advindas do gênero gótico e do horror. Praz (1996) menciona que este era um tema comum, principalmente relacionado ao satanismo romântico. Trata-seda ideia de uma figura errante, um anjo caído humanizado que seduz pelo ímpeto revolucionário e subversivo, que fascina pela noção de um grave delito ou pecado. Em nível metafísico e filosófico, é possível mencionar o comentário de Dyson e Lovelock: "Heaven is made by God, and is filled by Him; Hell is the experience of whatever consciousness is in exile from God" (DYSON; LOVELOCK, 1973, p. 228) ${ }^{13}$.Nesse sentido, o ideal satânico romântico, em muito revolucionário, compreenderia a busca pela existência exilada dos paradigmas estabelecidos.

caminho e se gaba disso, ainda assim, no fundo de sua mente há sempre a noção de que a maior aventura de sua vida começou à força, não por escolha. Tendo desistido de sua imortalidade, sabendo subconscientemente que James nunca devolveria seu corpo, Lestat agora tem a chance de fazer conscientemente essa escolha (Tradução do autor).

${ }^{11}$ Ele precisa recuperar seu corpo, do contrário, perderia sua identidade. Isto também reflete o desenvolvimento de sua caracterização, porque ele atingiu autoconhecimento suficiente não apenas para reconhecer o mal dentro de si mesmo, como também para abraçar tal parte de si mesmo (Tradução do autor).

12 "Este é a única forma pela qual o Diabo literal pode fazer o bem", Eu disse. "Interpretar a si mesmo para expor o mal" (Tradução do autor).

${ }^{13}$ O Paraíso é feito por Deus e preenchido por Ele; O Inferno é a experiência de o que quer que seja a consciência em exílio de Deus (Tradução do autor). 
Lestat escolhe o mal, pois seria a única forma pela qual ele poderia alcançar seu inferno interior, seu autorreconhecimento, que o poema de Blake é emblema.

Nessa perspectiva, The Tyger pode ser lido como um chamado ao reconhecimento do que há de temível, perigoso e destruidor em um indivíduo; algo que precisa ser assimilado para que possa haver um verdadeiro autoconhecimento. Da mesma forma que há necessidade de se reconhecer o tigre em cada ser humano, também existe a necessidade de que se reconheça o cordeiro. Ao tornarse humano, Lestat tenta reconhecer o cordeiro em si, que representa sua crença na existência da bondade. Porém, o tigre é sua natureza e, por isso, muito mais forte e sedutora para ele. Ao final do romance, no epílogo, ele precisa reconhecer o tigre para completar a si mesmo.

Ao final do romance, o personagem afirma: "I wanted to say something so terribly much! And would that it were full of poetry, and deep meaning, and would ransom my greed and my evil, and my lusty little heart" (RICE, 1993, p. 376) $)^{14}$. Mas nada pode ser dito, nada pode justificar sua escolha pelo mal e pela subversão, a não ser seu desejo autocentrado e sua natureza predatória. Como Lestat afirma: "[t]he tale is told" (RICE, 1993, p. 376) ${ }^{15}$. Por fim, Smith menciona que a busca de Lestat é "an internal quest to heal the missing parts of their unconscious selves" (1996, p. 97) ${ }^{16}$ e que ele acaba por aceitar "those parts even though they aren't the ideal selves they were hoping for" (1996, p. 98) ${ }^{17}$.

\section{Considerações finais}

O problema da tradução intersemiótica se relaciona diretamente com a questão da cultura como ponto de partida para a construção do conhecimento, principalmente porque envolve uma prática interdisciplinar. Em um terreno teórico

\footnotetext{
${ }^{14}$ Eu desejaria dizer algo terrivelmente temerário! E que isso fosse cheio de poesia e de significado, e que redimisse minha cobiça e meu mal, e meu cálido e lascivo coração (Tradução do autor).

${ }^{15}$ A história está contada (Tradução do autor).

${ }^{16}$ Uma jornada interna para curar as ausências de seu ser inconsciente (Tradução do autor).

${ }^{17}$ Aquelas partes de si que não eram o ideal que se esperava (Tradução do autor).
} 
comum, frequentemente aproxima-se da questão da interdisciplinaridade por dois vieses, o pedagógico e o epistemológico. O primeiro compreende a discussão de questões de natureza curricular, de formas de ensino e aprendizagem. Já o segundo se relaciona com categorias de estudo que se ocupam da produção de conhecimento, dos âmbitos sociais e reconstrutivos desse processo, voltado ao método de mediação entre realidade e sujeito. Ainda assim, vale ressaltar que os dois âmbitos abarcam conceitos diversos e complementares. A presença de discussões e atividades curriculares relativas à interdisciplinaridade é frequentemente vista não apenas como uma mudança pedagógica, mas como o resultado de uma profunda alteração nas diversas instâncias da vida social, tais como política, economia, tecnologia, literatura, artes visuais, entre outros. Pensar essas mudanças através da perspectiva interdisciplinar de estudo concorda com a afirmativa de Maria Cândida Moraes apresentada em $O$ paradigma educacional emergente (2002). A autora afirma a necessidade de uma forma educacional abrangente, multifacetada e complexa, capaz de abarcar uma realidade social tão múltipla quanto à contemporânea. Perspectiva que concorda com autores como Michael Gibbons (1997), para quem a interdisciplinaridade vem resolver o problema da fragmentação do conhecimento, incluindo seus processos de produção e disseminação. Pois, conforme Frigotto (1995), a interdisciplinaridade apresenta-se como algo dialético, caracterizado por conflitos e contradições, movimentos complexos de geração de conhecimento, emblema este, segundo o autor, da própria realidade social dos indivíduos. Dessa forma, é possível compreender que o estudo de problemas concernentes à tradução intersemiótica, campo amplo, multifacetado e sempre em expansão, vem a adensar questões e problemáticas metodológicas relativas à interdisciplinaridade.

O caráter intersemiótico entre a obra de Anne Rice e William Blake se desenvolve de forma múltipla. Em The Tale of the BodyThief, Rice emprega o poema The Tyger como uma espécie de emblema para a natureza e possibilidade de autorreconhecimento de Lestat. Os versos de Blake são uma potencial chave interpretativa para que se possa realizar não só uma leitura crítica sobre a obra de Rice, como também operam em nível ficcional, uma vez que o protagonista conhece o poema e menciona a obra em diversas passagens. Lestat reconhece o tigre e a carga simbólica que esse elemento carrega, então associa essa mesma carga 
simbólica a suas próprias angústias e convicções. Nessa acepção, o poema de Blake é semioticamente traduzido por Rice em duas instâncias. Na primeira delas, The Tyger opera como uma metáfora para a natureza do próprio vampiro Lestat, um predador terrível e belo, sublime em sua própria imagem. Na segunda instância, The Tyger relaciona-se com o romance de forma remissiva, diretamente ativa em relação à construção do enredo da obra.

Lestat questiona sua natureza, assim com a do mal e a de Deus, tenta abandonar seu próprio "eu", apenas para descobrir-se uma criatura de desejo autocentrado. Seria possível traçar um paralelo com a força retórica do poema de Blake, no entanto, o que mais me interessa aqui é discutir a tradução intersemiótica dos temas apresentados por Blake em seu poema, realizados por Rice em seu romance.Desse modo, o Lestat que se apresenta ao final da obra se relaciona diretamente com os versos finais do poema de Blake: "What immortal hand or eye/ Dare frame thy fearful symmetry" (BLAKE, 1789, v. 23-24) ${ }^{18}$.Como supracitado, o personagem menciona que gostaria de justificar "my greed and my evil, and my lusty little heart" (RICE, 1993, p. 376), coisa que é incapaz de fazer, pois Lestat não pode justificar sua natureza. De forma muito semelhante, não se pode justificar a natureza, a "fearful symmetry" do tigre de Blake, ele é o que é, belo e predatório, furioso e indiferente; resta apenas a força retórica que questiona quem ou que teria ousado (marcado pela troca do "could" para "dare", da primeira para a última estrofe) forjar tal criatura sublime, que vaga nas insólitas florestas da noite.

\section{REFERÊNCIAS}

AGUIAR, Daniella; QUEIROZ, João. Tradução intersemiótica: ação do signo e estruturalismo hierárquico. In: Revista do Programa de Pós-graduação em Comunicação Universidade Federal de Juiz de Fora (UFJF), v. 4, n. 1, 2010, p. 114.

BLAKE, William. The Tyger. In: Songs of Innocence and of Experience.Cópia L, 1795. Disponível em: <http://www.blakearchive.org >. Acesso em: 21/09/2015.

\footnotetext{
${ }^{18}$ Que olho ou mão armaria/ tua feroz symmetrya? (Tradução de Campos, 1979).
} 
The Marriage of Heaven and Hell, Cópia H, 1790-92. Disponível em: <http://www.blakearchive.org >. Acessoem: 21/09/2015.

O Tigre. In: CAMPOS, Augusto de. Viva Vaia (Poesia 1949-1979). São Paulo: Livraria Duas Cidades, 1979.

BLOOM, Harold. Critical Analysis of "The Tyger". In: BLOOM, Harold (Org.). Bloom's Major Poets: William Blake. New York: Infobase Publishing, 2003, p. 17-20.

BROWNE, Ray B; HOPPENSTAND, Gary. Vampires, Witches, Mummies, and Other Charismatic Personalities: Exploring the Anne Rice Phenomenon. In: BROWNE, Ray B; HOPPENSTAND, Gary (Org.). The Gothic World of Anne Rice. Bowling Green, OH: Bowling Green State University Popular Press, 1996, p. 1-13.

BUTLER. Judith P. Subjects of desire: Hegelian Reflections in TwentiethCentury France.New York: Columbia University Press, 1987.

CAMPOS, Haroldo de. Da tradução como criação e como crítica. In: Metalinguagem e outras metas: ensaios e crítica literária. São Paulo: Perspectiva, 2006.

CLÜVER, Claus. Da transposição intersemitótica. In: ARBEX, Márcia (Org.). Poéticas do visível: ensaios sobre a escrita e a imagem. Belo Horizonte: Programa de Pós-Graduação em Letras: Estudos Literários, Faculdade de Letras da UFMG, 2006.

DAMON, S. Foster. A Blake Dictionary - The Ideas and Symbols of William Blake.Hanover: DartmouthCollege Press, 2013.

ECO, Umberto. Quase a mesma coisa. Rio de Janeiro: Record, 2007.

FRIGOTTO, Gaudêncio. A interdisciplinaridade como necessidade e como problema nas ciências sociais. In: JANTSCH, Ari Paulo; BIANCHETTI, Lucídio (Orgs.). Interdisciplinaridade: para além da filosofia do sujeito. Petrópolis: Vozes, 1995.

GIBBONS, Michael et al. La nueva producción del conocimiento: la dinámica de la ciencia y la investigación en las sociedades contemporáneas. Barcelona: Pomares-Corredor, 1997.

JAKOBSON, Roman. Linguística e Comunicação. São Paulo: Cultrix, 2007.

MCGINLEY, Kathryn. Development of the Byronic Vampire: Byron, Stoker, Rice. In: BROWNE, Ray B; HOPPENSTAND, Gary (Org.). In: The Gothic World of Anne Rice. Bowling Green, OH: Bowling Green State University Popular Press, 1996, p. 71-90.

MORAES, Maria Cândida. O paradigma educacional emergente. São Paulo: Papirus, 2002. 
PAGLIARO, Harold. On the Changing View of "The Tyger". In: BLOOM, Harold (Org.). Bloom's Major Poets: William Blake. New York: Infobase Publishing, 2003, p. 22-26.

PEIRCE, Charles Sanders.Semiótica e Filosofia.São Paulo: Cultrix, 1972.

PLAZA, Julio. Tradução Intersemiótica. São Paulo: Perspectiva, 2008.

PRAZ, Mario. A Carne, a morte e o diabo na literatura romântica. São Paulo: Editora da Unicamp, 1996.

RICE, Anne. The vampire Lestat. New York City: Ballantine Books, 1987. The tale of the body thief. New York City: Ballantine Books, 1993.

ROBERTS, Garyn G. Gothicism, Vampirism, and Seduction: Anne Rice's "The Master of Rampling Gate". In: BROWNE, Ray B; HOPPENSTAND, Gary (Org.). The Gothic World of Anne Rice. Bowling Green, OH: Bowling Green State University Popular Press, 1996, p. 54-70.

SANTAELLA, Lucia. O que é semiótica?. São Paulo: Brasilliense, 2005.

SMITH, Jennifer. Anne Rice: A Critical Companion. Westport, CT: Greenwood Press, 1996.

DINIZ, Thaís Flores Nogueira. Tradução Intersemiótica: do texto para a tela. In: Cadernos de Tradução, v. 1, n. 3 (1998), p. 313-338. Disponível em: <https://periodicos.ufsc.br/index.php/traducao/article/view/5390/4934>. Acesso em: 10/02/2015

TAVARES, Enéias Farias. As Portas da Percepção: Texto e Imagem nos Livros lluminados de William Blake. Tese de Doutorado. Santa Maria: Universidade Federal de Santa Maria, 2012.

WOOD, Martin J. New life for old tradition: Anne Rice and Vampire Literature. In: The Blood is the Life: Vampires in Literature. Bowling Green, Ohio: Bowling Green State University Popular Press, 1999. 